\title{
Container survey of Aedes breeding sites in a Rural Health Training Centre campus in South West of Delhi
}

\author{
Arun Padmanandan', UV Venkatesh', DTiwar ${ }^{3}$ \\ 1,2,3 Department of Community Medicine, Vardhman Mahavir Medical College \& Safdarjung Hospital. \\ DOI: https://doi.org/10.24321/2455.7048.201808
}

\section{Abstract}

Introduction: Aedes mosquito is one of the mosquito species that are most studied because of their potential as vector of dengue and such information can be used to design an effective control measures for campuses.

Objective: To study the Aedes breeding sites using the container survey method and to recommend control measures in controlling the Aedes breeding sites.

Methodology: The container survey study was carried out in the campus of a Rural health training centre campus which spreads over 30 acres with rich plantation and trees all around. All natural and artificial containers in the vicinity of the campus and reachable tree holes were examined during the survey. The number, type and water condition of containers that may serve as potential breeding sites were examined and recorded. Larvae collection was carried out indoors (interior of the building) and outdoors (outside of the building but confined to its immediate vicinity within the campus limits) by using pre-designed questionnaire. Larva identification was done by motility Pattern.

Result: The survey included study of 359 common breeding sites such as cooler, Plastic storage containers, unused plastic waste, cement tanks, syntax tanks, earthen pots, plant pots, solid waste and others in 13 sites and 3 out of the 359 containers contained Aedes larvae.

Conclusion: The RHTC management should Practise Integrated Vector Management (IVM) recommended by WHO in the campus. An IVM approach takes into account the available health infrastructure and resources, and integrates all available and effective measures, whether chemical, biological or environmental.

Keywords: Aedes, Larva, Potential breeding site, Integrated vector management, Larval survey

\section{Introduction}

Dengue is a viral disease caused by RNA virus of Flaviviridae family. The global incidence of dengue is reportedly increasing with $>2.5$ billion people living at risk mostly in urban and sub-urban areas of tropical and sub-tropical countries with estimated 50-100 million cases annually (WHO, 2014). In India, the burden of Dengue was 1,11,896 cases and 227 deaths in $2016^{1}$. The total number of cases has almost doubled since $2012^{1}$.The disease is transmitted mainly by the infective bite of Aedes aegypti mosquito and another important vector involved is Aedes albopictus. Disease develops 5-6 days after being bitten by an infective mosquito. The favoured breeding places of the vector include-desert coolers, drums, jars, pots, buckets, flower vases, plant saucers, tanks, cisterns, bottles, tins, tyres, roof gutters, refrigerator drip pans, cement blocks, cemetery urns, bamboo stumps, coconut shells, tree holes and many more places where rainwater collects or is stored ${ }^{2}$.

Corresponding Author: Dr. Arun Padmanandan, Department of Community Medicine, Vardhman Mahavir Medical College \& Safdarjung Hospital.

E-mail Id: arun.padmanandan@gmail.com

Orcid Id: https://orcid.org/0000-0002-0663-3162

How to cite this article: Padmanandan A, Venkatesh U, Tiwari P. Container survey of Aedes breeding sites in a Rural Health Training Centre campus in South West of Delhi. Epidem Int 2018; 3(2): 6-9. 
Disease is prevalent throughout India in most of the metropolitan cities and towns ${ }^{3}$. Containers are probably the most important factor determining the breeding of Aedes spp. since artificial containers are the major larval habitats in and near human habitation ${ }^{4}$. The life cycle of mosquito is completed by 7-10 days 5 . The vector can fly only upto a limited range of $400 \mathrm{~m}$, but can spread over vast distances mechanically in various types of vehicles used by $\operatorname{man}^{6}$.There are many factors that have contributed to this emergence of dengue, but the principal drivers are urbanization, globalization and lack of effective mosquito control. Mosquito larvae go through four developmental stages called instars, usually referred to as 1 st to 4 th instar larvae, which eventually turn into pupae. In Aedes breeding, when the larval and pupal count combined value exceeds $>5 /$ dip and if $>25 \%$ of all samples are positive for immature mosquitoes, that is the threshold for control action?

Larval sampling should be systematic. It should take into account temporal and spatial coverage. Larval sampling sites should include either fixed or random sampling (or both) depending upon whether the habitats are permanent or temporary in nature ${ }^{8,9,10}$. However when located near human inhabitation, larval counts of $>2$ larvae/dip in manmade containers or natural habitats might warrant control. For Aedes, a House Index of $>5 \%$ and Breteau Index of $>20 \%$ should alarm and warrant immediate control action at PoE. Various threshold levels have been suggested for native mosquitoes based on different levels of incidence and types of traps. In Delhi, Aedes mosquito is one of the mosquito species that are most studied because of their potential as vector of dengue and the present survey was therefore conducted to determine the container breeding preferences of mosquitoes by larval survey in the campus of the RHTC, Najafgarh, Delhi. Such information can be used to design an effective control measures for campuses. With this background our objective was to study the Aedes breeding sites using the container survey method and to recommend control measures in controlling the Aedes breeding sites.

\section{Methodology}

The container survey study was carried out from 19 October 2017 to 25 October 2017, in the campus of Rural health training centre campus in south west Delhi at Najafgarh, which spreads over 30 acres with rich plantation and trees all around.

All natural and artificial containers in the vicinity of the campus and reachable tree holes were examined during the survey. The number, type and water condition of containers that may serve as potential breeding sites were examined and recorded. Larvae collection was carried out indoors (interior of the building) and outdoors (outside of the building but confined to its immediate vicinity within the campus limits) by using pre-designed questionnaire. Larva identification was done by motility Pattern.

The survey areas included Coolers, plastic storage containers, unused plastic waste, cement and syntax tanks, earthen pots, solid waste and others was examined.

\section{Results}

The survey included study of 359 common breeding sites such as cooler, Plastic storage containers, unused plastic waste, cement tanks, syntax tanks, earthen pots, plant pots, solid waste and others in 13 sites such as the New Director office, Cold chain storage building, MCD Malaria office, Old Director office, Staff Quarters 1, Staff Quarters 2, ANM Hostel, ANM School, Auditorium, ANC OPD, DOTS Centre, OPD Building, Metro construction site within the campus premises and 3 out of the 359 containers contained Aedes larvae as shown in Table 1.

Table 1.Premises wise distribution of searched $\&$ Larval positive containers

\begin{tabular}{|c|c|c|c|c|c|c|c|c|c|c|c|c|c|c|c|c|c|c|}
\hline \multirow{3}{*}{\begin{tabular}{l}
\multicolumn{1}{c}{ Premises } \\
$\begin{array}{l}\text { New Director } \\
\text { office }\end{array}$
\end{tabular}} & \multicolumn{2}{|c|}{ Cooler } & \multicolumn{2}{|c|}{ Plastic storage } & \multicolumn{2}{|c|}{ Plastic unused } & \multicolumn{2}{|c|}{ Cement tanks } & \multicolumn{2}{|c|}{ Syntax tanks } & \multicolumn{2}{|c|}{$\begin{array}{l}\text { Earthen } \\
\text { (MP/BP) }\end{array}$} & \multicolumn{2}{|c|}{$\begin{array}{l}\text { Planted Pot } \\
(C / E / P)\end{array}$} & \multicolumn{2}{|c|}{ Solid Waste } & \multicolumn{2}{|l|}{ Others } \\
\hline & \multicolumn{2}{|c|}{ Search +ve } & \multirow{2}{*}{$\begin{array}{l}\text { Search } \\
3\end{array}$} & $+\mathrm{ve}$ & \multirow{2}{*}{$\begin{array}{l}\text { Search } \\
2\end{array}$} & +ve & \multicolumn{2}{|c|}{ Search +ve } & \multicolumn{2}{|c|}{ Search +ve } & \multicolumn{2}{|c|}{ Search +ve } & \multicolumn{2}{|c|}{ Search +ve } & \multirow{2}{*}{\begin{tabular}{|l|} 
Search \\
4
\end{tabular}} & +ve & \multirow{2}{*}{$\begin{array}{l}\text { Search } \\
4\end{array}$} & \multirow{2}{*}{$\frac{+\mathrm{v}}{0}$} \\
\hline & 0 & 0 & & 1 & & 0 & 0 & 0 & 0 & 0 & 0 & 0 & 0 & 0 & & 0 & & \\
\hline $\begin{array}{l}\text { Cold chain } \\
\text { storage } \\
\text { building }\end{array}$ & 4 & 0 & 2 & 0 & 12 & 0 & 0 & 0 & 0 & 0 & 0 & 0 & 4 & 0 & 10 & 0 & 4 & 0 \\
\hline $\begin{array}{l}\text { MCD Malaria } \\
\text { office }\end{array}$ & 2 & 0 & 2 & 0 & 2 & 0 & 0 & 0 & 0 & 0 & 2 & 0 & 4 & 0 & 3 & 0 & 1 & 0 \\
\hline Director office & 6 & 0 & 0 & 0 & 10 & 0 & 0 & 0 & 2 & 0 & 1 & 0 & 13 & 0 & 0 & 0 & 2 & 0 \\
\hline $\begin{array}{l}\text { Staff Quarters } \\
1\end{array}$ & 4 & 0 & 3 & 0 & 42 & 0 & 1 & 0 & 2 & 0 & 10 & 0 & 14 & 0 & 22 & 0 & 12 & 0 \\
\hline $\begin{array}{l}\text { Staff Quarters } \\
2\end{array}$ & 2 & 0 & 12 & 1 & 8 & 0 & 0 & 0 & 2 & 0 & 3 & 0 & 4 & 0 & 22 & 0 & 10 & 1 \\
\hline ANM Hostel & 12 & 1 & 6 & 0 & 5 & 0 & 0 & 0 & 8 & 0 & 0 & 0 & 0 & 0 & 2 & 0 & 2 & 0 \\
\hline ANM School & 0 & 0 & 4 & 0 & 0 & 0 & 0 & 0 & 0 & 0 & 0 & 0 & 19 & 0 & 0 & 0 & 1 & 0 \\
\hline Auditorium & 0 & 0 & 4 & 0 & 0 & 0 & 0 & 0 & 0 & 0 & 0 & 0 & 0 & 0 & 0 & 0 & 0 & 0 \\
\hline ANC OPD & 0 & 0 & 0 & 0 & 4 & 0 & 0 & 0 & 0 & 0 & 0 & 0 & 0 & 0 & 0 & 0 & 0 & 0 \\
\hline DOTS Centre & 1 & 0 & 0 & 0 & 2 & 0 & 0 & 0 & 0 & 0 & 0 & 0 & 4 & 0 & 0 & 0 & 1 & 1 \\
\hline OPD Building & 1 & 0 & 0 & 0 & 6 & 0 & 0 & 0 & 0 & 0 & 0 & 0 & 0 & 0 & 1 & 0 & 1 & 0 \\
\hline $\begin{array}{l}\text { Metro } \\
\text { construction } \\
\text { site }\end{array}$ & 0 & 0 & 0 & 0 & 0 & 0 & 0 & 0 & 0 & 0 & 0 & 0 & 0 & 0 & 0 & 0 & 1 & 0 \\
\hline
\end{tabular}

$=$ Mud Plot, $\mathrm{BP}=$ Bird Pot, $\mathrm{C}=$ Cement pot, $\mathrm{E}=$ Earthen pot, $\mathrm{P}=$ Plastic pot; Solid waste includes tyres, unused cup, broken glasses 


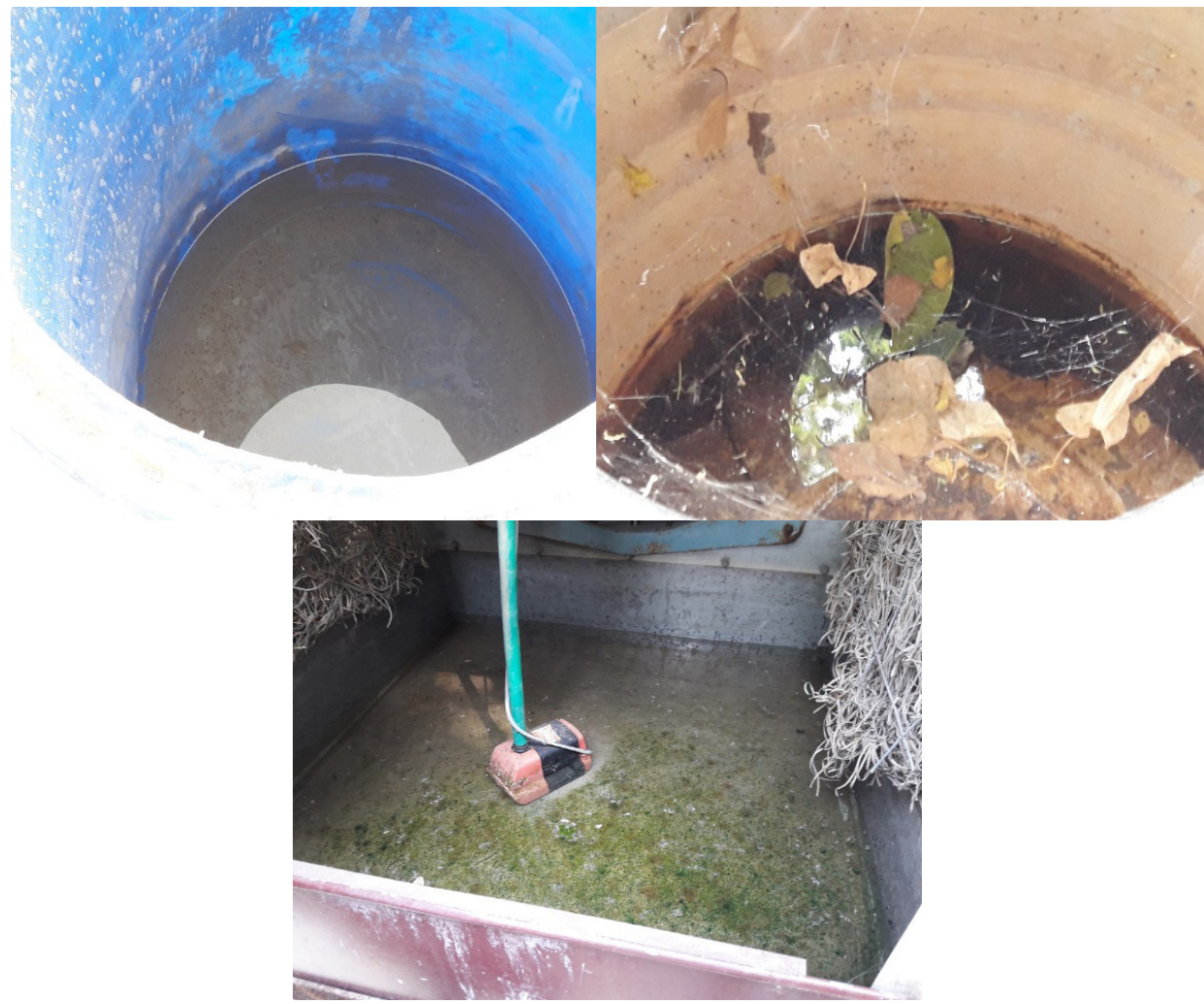

Figure 1.Larvae Positive containers
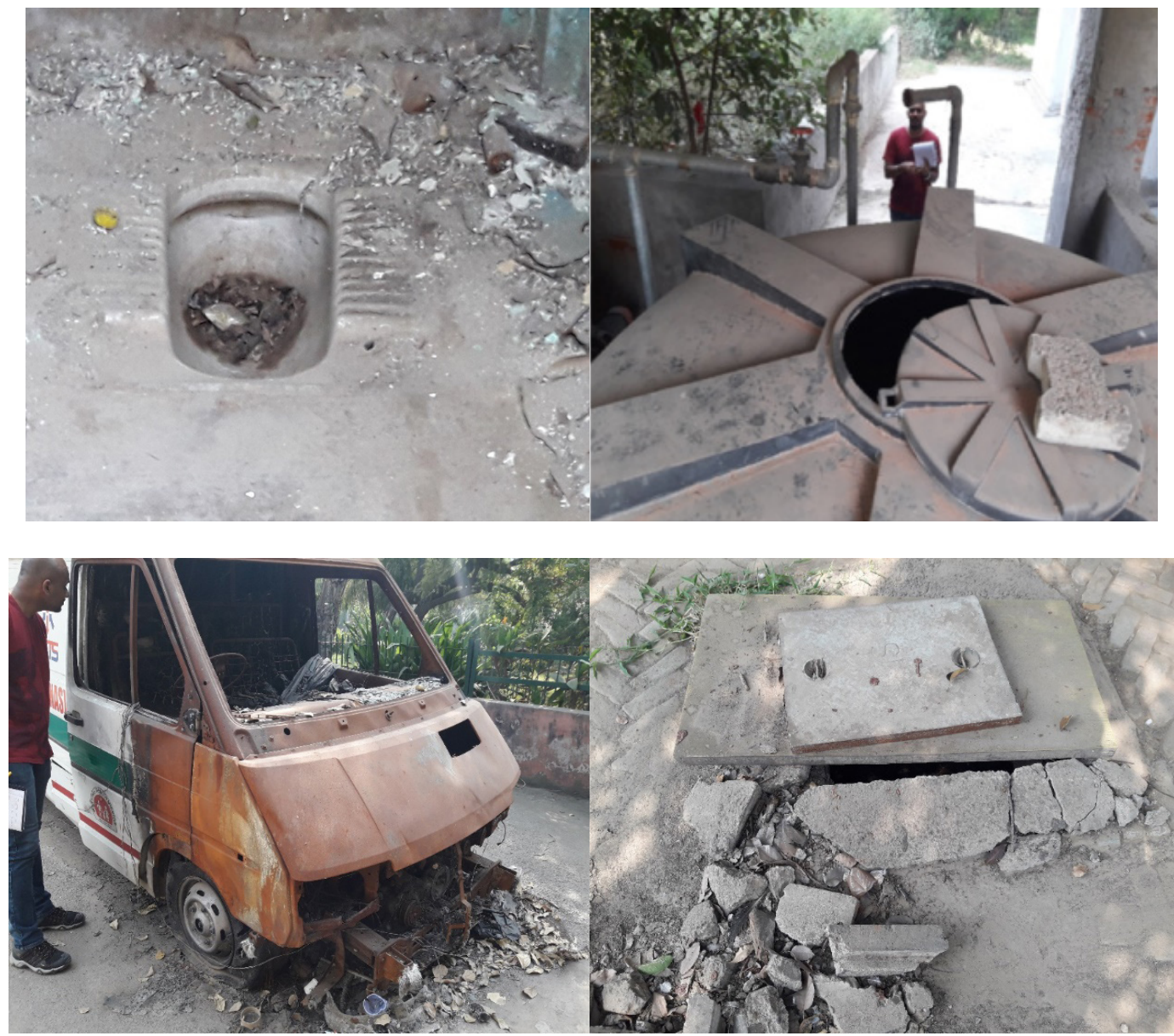

Figure 2.Some Potential breeding sites 


\section{Conclusion}

The study has clearly shown again that artificial man-made containers are the potential breeding site for Aedes larvae when water collects in them. These containers as already said are man-made and each individual must take up the responsibility by avoiding the same. Hence, Integrated vector management along with Health education of the masses will help in eliminating vector borne diseases. The elimination of artificial and natural containers or alteration of breeding sites in and around living/working areas of RHTC campuses, should be taken into consideration since the presence of water in containers is probably the most important factor in determining the breeding of mosquitoes, especially Aedes. Container management should be taken up as a priority by the campus community.

The RHTC management should Practise Integrated Vector Management (IVM) recommended by WHO in the campus. An IVM approach takes into account the available health infrastructure and resources, and integrates all available and effective measures, whether chemical, biological or environmental. IVM also encourages effective coordination of the control activities of all sectors that have an impact on vector-borne diseases, including health, water, and solid waste and sewage disposal. An IVM approach is evidencebased and its essential feature is the development of capacity to generate local data on disease epidemiology and vector ecology. IVM integrates all available resources to achieve maximum impact on vector-borne diseases. However, integration of IVM at the recommended by WHO in the campus. An IVM approach takes into account the available health infrastructure and resources, and integrates all available and effective measures, whether chemical, biological or environmental. IVM also encourages effective coordination of the control activities of all sectors that have an impact on vector-borne diseases, including health, water, and solid waste and sewage disposal. An IVM approach is evidence-based and its essential feature is the development of capacity to generate local data on disease epidemiology and vector ecology. IVM integrates all available resources to achieve maximum impact on vectorborne diseases. However, integration of IVM at the level required is not a simple task. Commitment is needed from the RHTC management to integrate IVM within the campus and local health authorities to coordinate their efforts.

\section{Conflict of Interest: None}

\section{References}

1. Central Bureau of Health Intelligence - India [Internet]. [cited 2018 Apr 20]. Available from: http://cbhidghs. nic.in/index2. asp?slid=1326\&sublinkid=1178.

2. NVBDCP | National Vector Borne Disease Control Programme [Internet]. [cited 2018 Apr 20]. Available from: http://nvbdcp.gov.in/DENGU1.html.

3. Dutta P, Mahanta J. Potential vectors of dengue and the profile of dengue in the North-Eastern Region of India: An epidemiological perspective. Dengue Bulletin 2006;30:234-42.

4. Lee HL. A nationwide resurvey of the factors effecting the breeding of Aedes aegypti and Aedes albopictus in urban towns of Peninsular Malaysia - 1988- 1989. Tropical Biomedicine 1991;8:151-60.

5. Directorate of National vector borne disease control programme. Operational manual on Integrated Vector Management in India.

6. Bhalwar R. Text book of public health and community medicine. Pune: Department of Community Medicine Armed Forces Medical College; 2009.

7. Strickman D, Kittayapong P. Dengue and its vectors in Thailand: calculated transmission risk from total pupal counts of Aedes aegypti and association of wing-length measurements with aspects of the larval habitat. $A m$ J Trop Med Hyg 2003 Feb;68(2):209-17.

8. Pitisuttithum P, Bouckenooghe A. The first licensed dengue vaccine: an important tool for integrated preventive strategies against dengue virus infection.

9. Dame D, Fasulo TR. Mosquitoes in Public health pesticide applicator training manual for USA and its territories. Gainesville: University of Florida, 2003.

10. Chen CD, Lee HL, Wong SPS, Lau KW, Azirun MS. Container survey of mosquito breeding sites in a university campus in Kuala Lumpur Malaysia. Dengue Bulletin 2009;33:1-7.

Date of Submission: 2018-05-01 Date of Acceptance: 2018-05-14 